\title{
PET/MRI: a novel hybrid imaging technique. Major clinical indications and preliminary experience in Brazil
}

\author{
PET/RM: um novo método de imagem híbrida. \\ Principais indicações clínicas e experiência preliminar no Brasil
}

\author{
Taise Vitor ${ }^{1}$, Karine Minaif Martins ${ }^{1}$, Tudor Mihai Ionescu ${ }^{1}$, Marcelo Livorsi da Cunha ${ }^{1}$, Ronaldo Hueb Baroni ${ }^{1}$, \\ Marcio Ricardo Taveira Garcia ${ }^{1}$, Jairo Wagner ${ }^{1}$, Guilherme de Carvalho Campos Neto ${ }^{1}$, \\ Solange Amorim Nogueira ${ }^{1}$, Elaine Gonçalves Guerra ${ }^{1}$, Edson Amaro Junior ${ }^{1}$
}

\begin{abstract}
In recent years, medical imaging with hybrid techniques has widely accepted and employed in clinical routine. PET/MRI offers significant advantages, including excellent contrast and resolution and reduced ionizing radiation, as compared to well-established PET/ CT. Therefore, PET/MRI is a promising modality for oncologic imaging of some regions, such as brain, head and neck, liver and pelvis. This article set out to analyze clinical conditions that could benefit from PET/MRI imaging based on our caseload. The potential of PET/MRI to become the imaging modality of choice for assessment of neurologic and oncologic conditions associated with soft tissues is highlighted. Clinical aspects of PET/MRI and its application to clinical cases are illustrated with examples extracted from the authors' preliminary experience.
\end{abstract}

Keywords: Positron-emission tomography/methods; Magnetic resonance imaging/methods; Tomography, x-ray computed/methods; Pelvic neoplasms; Prostatic neoplasms; Neuroimaging

\section{RESUMO}

Nos últimos anos, imagens médicas com tecnologias híbridas tornaram-se amplamente aceitas e utilizadas na prática clínica. 0 PET/ RM possui vantagens importantes, incluindo excelentes contrastes e resolução, e menor radiação ionizante, em comparação ao PET/TC. Por isto, é uma modalidade promissora para exames de imagem de pacientes oncológicos, para avaliar o cérebro, cabeça e pescoço, 0 fígado e a pelve. 0 objetivo deste artigo foi analisar as situações clínicas que se beneficiariam de exames de PET/RM a partir de uma casuística. Destacamos o potencial desta técnica se tornar o método de imagem de escolha para doenças neurológicas e oncológicas que envolvam partes moles. Os aspectos clínicos de PET/RM e sua aplicação aos casos clínicos são ilustrados com exemplos da experiência inicial dos autores.
Descritores: Tomografia por emissão de pósitrons/métodos; Imagem por ressonância magnética/métodos; Tomografia computadorizada por raios x/métodos; Neoplasias pélvicas; Neoplasias da próstata; Neuroimagem

\section{INTRODUCTION}

Positron emission tomography (PET) was developed by Ter-Pogossian et al., in the 1970s, and implemented in clinical practice in the late 1980 s and early 1990s. ${ }^{(1)}$

The first whole-body integrated $\mathrm{PET} /$ magnetic resonance imaging (PET/MRI) system has been recently introduced. The adoption of PET/MRI has been much slower compared to PET/computed tomography (PET/ CT). Since its introduction in 2010, approximately 70 systems have been installed worldwide, mostly in universities. ${ }^{(2)}$ Equipment costs, operational costs and related logistics are thought to account for the slow adoption of the method. Furthermore, diagnostic benefits compared to well-established high performance modalities, such as PET/CT, are difficult to prove. Potential advantages of PET/MRI include high soft tissue contrast and functional MRI capability. ${ }^{(2)}$

This novel technology can provide simultaneous anatomic and molecular information and may come to achieve similar success to PET/CT, particularly in oncologic conditions, in which MRI is more indicated than CT due to improved soft tissue contrast. Magnetic resonance imaging is the current imaging modality of choice for oncological conditions associated with soft tissues (e.g., brain, head and neck, liver and pelvis). ${ }^{(3)}$

\footnotetext{
Hospital Israelita Albert Einstein, São Paulo, SP, Brazil.

Corresponding author: Taise Vitor - Avenida Albert Einstein, 627/701 - Morumbi - Zip code: 05652-900 - São Paulo, SP, Brazil - Phone: (55 11) 2151-4963 - E-mail: taisevitor@gmail.com

Received on: June 28, 2016 - Accepted on: Oct 30, 2016
}

DOI: 10.1590/S1679-45082017MD3793 
The aim of this paper is to describe and evaluate clinical aspects related to the use of PET/MRI in oncologic and neurologic diagnosis, and to illustrate the application of this imaging modality with examples extracted from the authors' caseload and preliminary experience.

\section{METHODS}

Five clinical cases involving patients referred to our institution for PET/CT are described in this article. Patients were submitted can PET/MRI immediately after $\mathrm{PET} / \mathrm{CT}$, without any further intravenous contrast agent injection for improved lesion characterization. Image acquisition was performed between 60 and 90 minutes, after intravenous injection of 148 to $333 \mathrm{MBq}$ of specific radiotracers $\left({ }^{18} \mathrm{~F}-\mathrm{FDG}\right.$, Fluorodeoxyglucose or ${ }^{68} \mathrm{Ga}$-PSMA, prostate-specific membrane antigen labeled with ${ }^{68} \mathrm{Ga}$ ). Scanning time ranged from 30 to 90 minutes; images with high anatomical resolution and excellent soft tissue contrast were obtained.

\section{PET/MRI}

PET/MRI with attenuation correction were acquired using dual echo VIBE Dixon or ultrashort echo time sequences for water and fat or bone separation. Anatomical MRI sequences were selected according to the type of exam (whole-body, head and neck, female and male pelvis or neurologic protocols). Simultaneous acquisition of PET images was performed using the following parameters: $500 \mathrm{~mm}$ FOV, $400 \mathrm{~mm}$ anteriorposterior FOV, 1.0 zoom, 3 interactions, 21 subsets, HD PET reconstruction method, and $2.0 \mathrm{~mm}$ Gaussian filter (oncological assessment); or $300 \mathrm{~mm}$ FOV, $300 \mathrm{~mm}$ anterior-posterior FOV, 1.0 zoom, 8 interactions, 21 subsets, HD PET reconstruction and $2.0 \mathrm{~mm}$ Gaussian filter (neurological assessment).

\section{Whole-body PET/MRI in oncology}

Whole-body PET/MRI is particularly indicated in cases requiring both the advantages of PET in detecting extramedullary disease, and the superiority of MRI in detecting spinal cord compression, extramedullary disease and active post-treatment residual sites. Therefore this novel technology is an attractive alternative for multiple myeloma and bone metastasis assessment $^{(4)}$ (Figure 1).
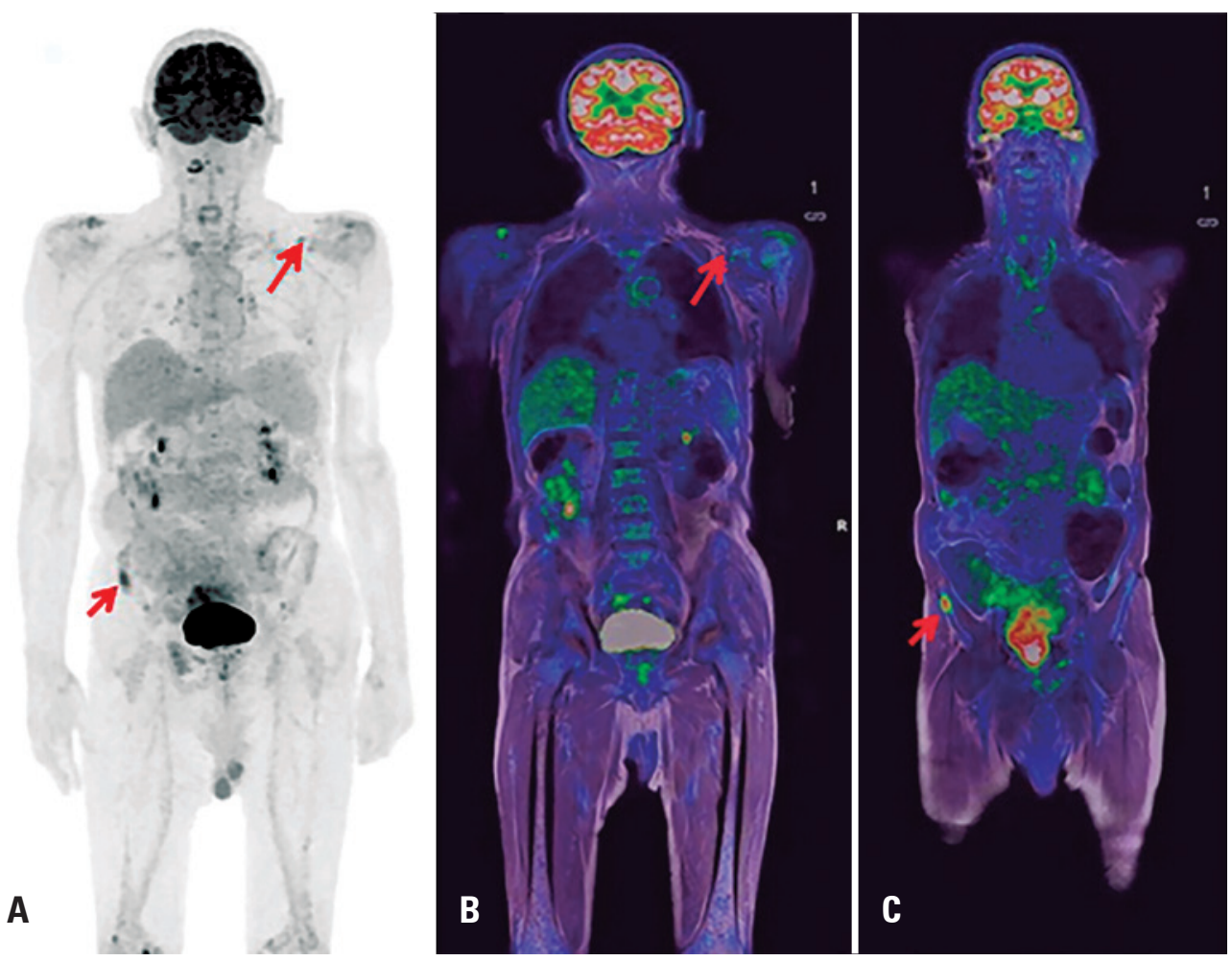

Figure 1. Post-chemotherapy whole-body ${ }^{18} \mathrm{~F}-\mathrm{FDG}$ PET/MRI images of a male patient with multiple myeloma, showing residual metabolic activity in the right iliac crest and hypermetabolic left supraclavicular lymph node (arrows). (A) PET, maximum intensity projection image; (B and C) fused PET/MRI image, coronal T1 


\section{Head-and-neck PET/MRI}

The role of PET/MRI in head and neck cancer diagnosis was first investigated by Boss et al. ${ }^{(5)}$ This imaging modality is attractive due to superior soft tissue contrast and the lower susceptibility of MRI to artifacts generated by dental metallic implants compared to $\mathrm{CT}^{(6)}$

High spatial resolution and contrast of MRI are vital for tumor and regional lymph node staging in this complex anatomical region, given the ability of the method to delineate the actual tumor extent and distinguish lymph node involvement from surrounding normal tissue. Also, PET/MRI can be useful to detect distant metastatic spread, thereby contributing to radiation therapy and preoperative treatment planning (Figure 2).
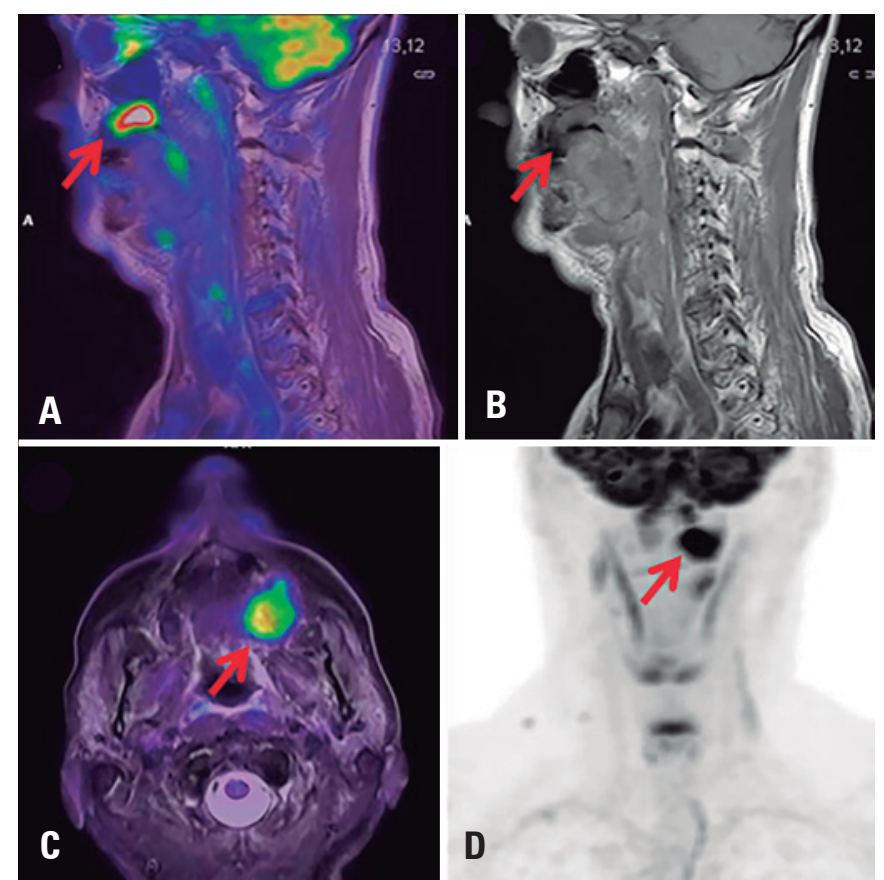

Figure 2. Head-and-neck ${ }^{18} \mathrm{~F}-\mathrm{FDG}$ PET/MRI images showing hypermetabolic uptake in the left anterior portion of the gum line, extending to adjacent structures. (A) fused PET/MRI image, sagittal T1; (B) sagittal T1; (C) fused PET/MRI image, axial T2 fat saturated; (D) PET, maximum intensity projection image (arrows)

\section{PET/MRI of the female pelvis}

According to the National Comprehensive Cancer Network (NCCN) guidelines, PET/CT and PET/MRI are indicated as supplemental exams in cases suspected of gross cervical involvement or extrauterine disease. ${ }^{(7)}$ PET/MRI provides higher diagnostic confidence for discrimination between benign and malignant lesions compared to PET/CT (Figure 3).

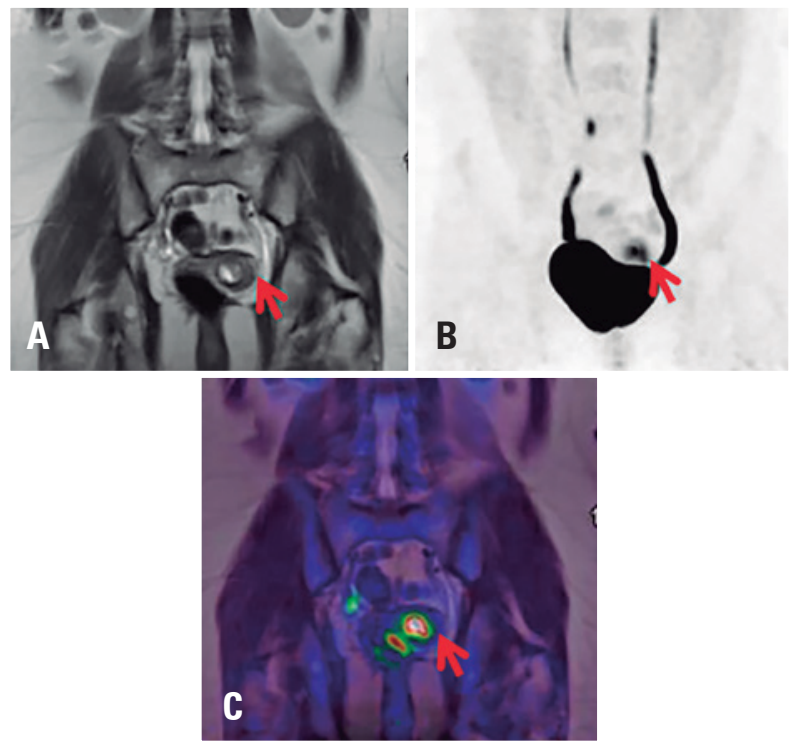

Figure 3. ${ }^{18} \mathrm{~F}-\mathrm{FDG} \mathrm{PET} / \mathrm{MRI}$ images of a female pelvis with invasive adenocarcinoma of the cervix showing metabolic activity in the left uterine wall, near the uterine cavity. (A) Dixon VIBE, coronal T2; (B) PET, maximum intensity projection image; (C) fused PET/MRI image, coronal T2

\section{PET/MRI of the male pelvis}

Multiparametric MRI (mpMRI) can be combined with ${ }^{68} \mathrm{Ga}$-PSMA PET for recurrent prostate cancer detection, staging and assessment. Superior results have been reported in the evaluation of the prostatic bed

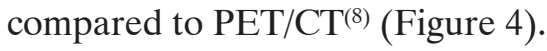

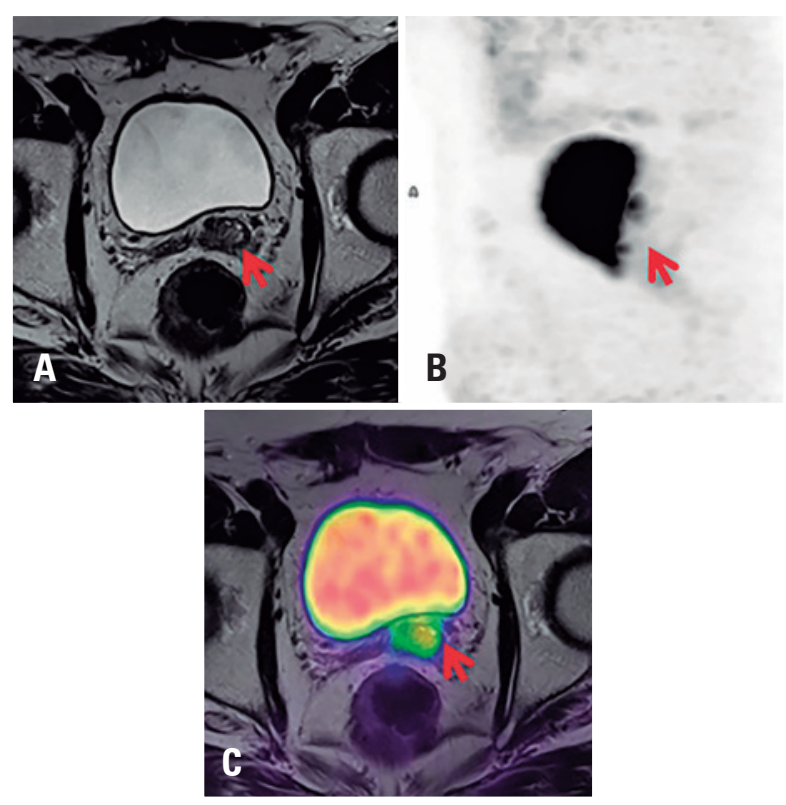

Figure 4. ${ }^{68} \mathrm{Ga}-\mathrm{PSMA} \mathrm{PET} / \mathrm{MRI}$ image of a pelvis with recurrent prostate carcinoma in left seminal vesicle remnant, and marked PSMA expression in the lesion. (A) MRI image, axial T2; (B) PET, maximum intensity projection image; (C) fused PET/MRI image, axial T2 


\section{PET/MRI in neurology}

Magnetic resonance imaging is the modality of choice for neuro-oncologic imaging, neurodegenerative diseases and epilepsy. ${ }^{(2,9)}$ Multimodal PET/MRI can provide functional information for easier recognition of degeneration patterns specific to Parkinson's disease, multiple system atrophy, progressive supranuclear palsy and corticobasal degeneration $^{(10)}$ (Figure 5).
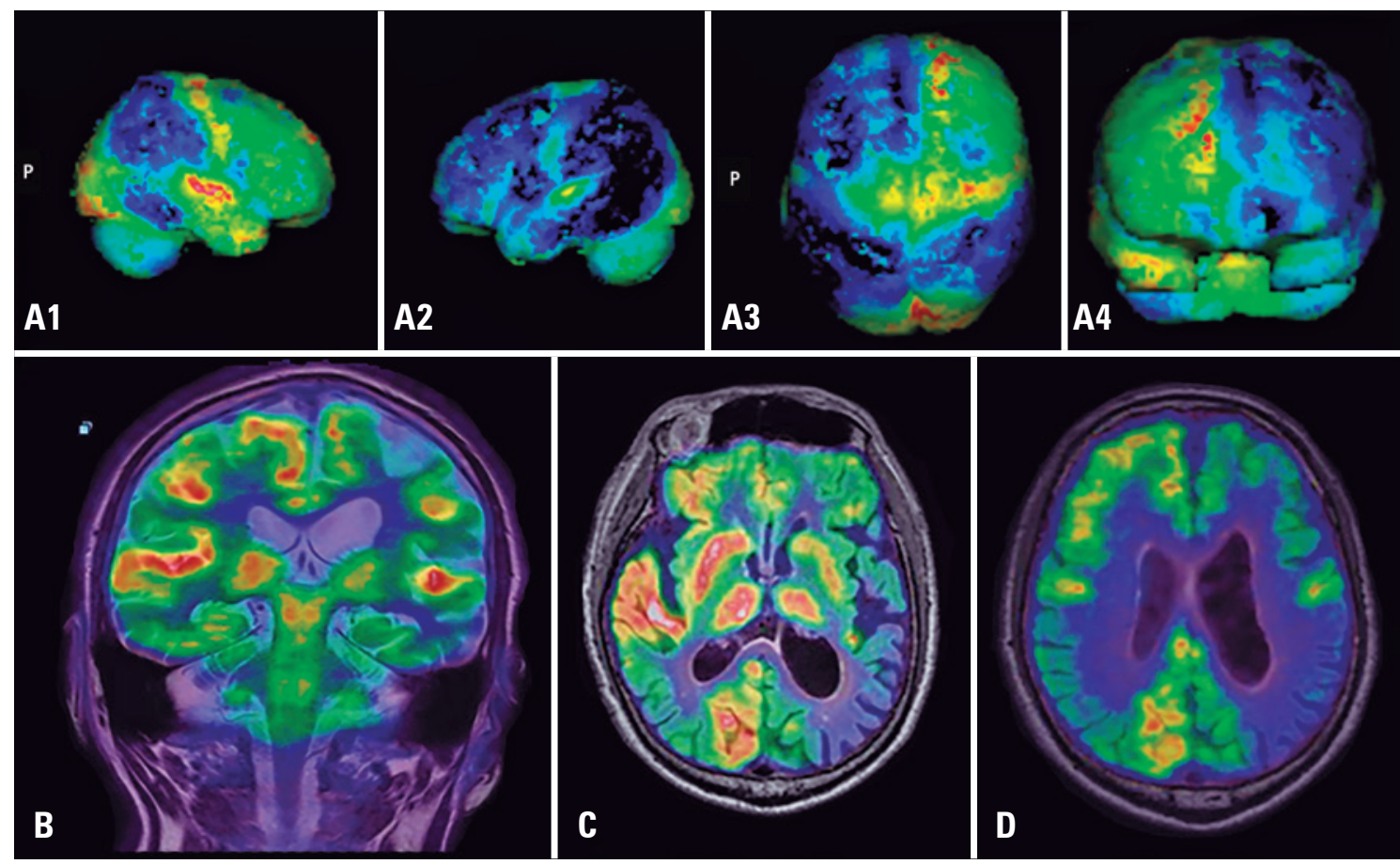

Figure 5. Brain ${ }^{18} \mathrm{~F}-\mathrm{FDG}$ PET/MRI images of a male patient with Parkinson's disease and cognitive impairment, showing glucose metabolism deficit and volumetric reduction in the left cerebral hemisphere. Similar findings can be seen in Lewy body dementia. (A1, $A 2, A 3, A 4)$ PET, volumetric reconstructions; (B) coronal T2; (C and D) fused PET/MRI images (FLAIR)

\section{CONCLUSION}

PET/MRI is among the most exciting recent developments in non-invasive hybrid imaging; the combination of anatomical and functional imaging modalities and the use of different tracers to provide comprehensive valuable information. Growing experience with PET/ MRI suggests it could become the imaging modality of choice, particularly for assessment of some regions, such as brain, head and neck, liver and pelvis. However, widely accepted clinical indications remain to be determined before conclusive statements regarding the advantages of PET/MRI, over PET/CT can be made.

\section{REFERENCES}

1. Ter-Pogossian MM, Phelps ME, Hoffman EJ, Mullani NA. A positron-emission transaxial tomograph for nuclear imaging (PETT). Radiology. 1975;114(1):89-98.

2. Spick C, Herrmann K, Czernin J. 18F-FDG PET/CT and PET/MRI perform equally well in cancer: evidence from studies on more than 2,300 patients. J Nucl Med. 2016;57(3):420-30. Review.
3. Pichler BJ, Kolb A, Nägele T, Schlemmer HP. PET/MRl: paving the way for the next generation of clinical multimodality imaging applications. J Nucl Med. 2010;51(3):333-6.

4. Barley K, Chari A. Diagnostic advances in multiple myeloma. Curr Hematol Malig Rep. 2016;11(2):111-7. Review.

5. Boss A, Stegger L, Bisdas S, Kolb A, Schwenzer N, Pfister M, et al. Feasibility of simultaneous PET/MR imaging in the head and upper neck area. Eur Radiol. 2011;21(7):1439-46.

6. Partovi S, Kohan A, Vercher-Conejero JL, Rubbert C, Margevicius S, Schluchter $\mathrm{MD}$, et al. Qualitative and quantitative performance of ${ }^{18} \mathrm{~F}-\mathrm{FDG}-\mathrm{PET} / \mathrm{MRI}$ versus ${ }^{18} \mathrm{~F}-\mathrm{FDG}-\mathrm{PET} / \mathrm{CT}$ in patients with head and neck cancer. AJNR Am J Neuroradiol. 2014;35(10):1970-5.

7. National Comprehensive Cancer Network (NCCN). NCCN Guidelines ${ }^{\circledR}$. NCCN guidelines for treatment of cancer by site. Cervical cancer [Internet]. Fort Washington: NCCN; 2016 [cited 2017 Jan 30]. Available from: https://www. nccn.org/professionals/physician_gls/f_guidelines.asp

8. Afshar-Oromieh A, Haberkorn U, Schlemmer HP, Fenchel M, Eder M, Eisenhut $\mathrm{M}$, et al. Comparison of PET/CT and PET/MRI hybrid systems using a 68Ga labelled PSMA ligand for the diagnosis of recurrent prostate cancer: initial experience. Eur J Nucl Med Mol Imaging. 2014;41(5):887-97.

9. National Comprehensive Cancer Network (NCCN). NCCN Guidelines ${ }^{\circledR}$. NCCN guidelines for treatment of cancer by site. Central nervous system cancer [Internet]. Fort Washington: NCCN; 2016 [cited 2017 Jan 30]. Available from: https://www.nccn.org/professionals/physician_gls/f_guidelines.asp

10. Afaq A, Syed R, Bomanji J. PET/MRl: a new technology in the field of molecular imaging. Br Med Bull. 2013;108:159-71. Review. 